\title{
Exposure Factors Influence Stone Deterioration by Crystallization of Soluble Salts
}

\author{
Enrique Gil, ${ }^{1}$ Ángeles Mas, ${ }^{2}$ Carlos Lerma, ${ }^{2}$ and Jose Vercher ${ }^{2}$ \\ ${ }^{1}$ Departmento de Mecánica de los Medios Continuos y Teoría de Estructuras, Universitat Politècnica de València, \\ Camino de Vera, s/n, 46022 Valencia, Spain \\ ${ }^{2}$ Departmento de Construcciones Arquitectónicas, Universitat Politècnica de València, Camino de Vera, s/n, 46022 Valencia, Spain
}

Correspondence should be addressed to Carlos Lerma; clerma@csa.upv.es

Received 13 March 2015; Accepted 20 March 2015

Academic Editor: João M. P. Q. Delgado

Copyright (C) 2015 Enrique Gil et al. This is an open access article distributed under the Creative Commons Attribution License, which permits unrestricted use, distribution, and reproduction in any medium, provided the original work is properly cited.

\begin{abstract}
The present work tries to determine the factors that influence the crystallization of soluble salts in the stone material used in the construction of buildings in Valencia (Spain). Samples are obtained from a building which has served to accomplish observations and laboratory experiments necessary in order to determine the pathology of deterioration of the material. It was particularized in the exposition conditions of the material as a base for determining the morphologies of deterioration caused by salts in the same lithotype. The main contribution is the petrological study from the architectural point of view considering its orientation, sunlight in façade, and so forth. This study proves that both material petrology (its mineralogy and texture) and the properties related to the movement of water inside rocks play a decisive role in the conservation and development of elements in the alteration.
\end{abstract}

\section{Introduction}

To perform this studio we focus on the stone obtained from the Church of Santos Juanes in Valencia. The Church of Santos Juanes is situated, within its enclave, in the historic centre of Valencia, in an area delimited by and known as the Barrio del Mercat (market neighborhood). The group of dwellings in this quarter, as with many others that form part of the city, are characterized by belonging to, and forming part of, the urban history of the city of Valencia [1].

During this time the church and its surroundings were subjected to different transformations and reformations that have characterized this site [2]. Because of the traditionally commercial character of the Barrio del Mercat, from the 16th century, the church became the backdrop to the trading centre, with typical itinerant market stalls propped up against its façade. The sitting of the Central Market at the beginning of the 20th century, together with the Lonja de Mercado (Market Exchange), caused the permanent presence of dampness brought about by the daily washing routine.

The construction of this building transformed the public character of the market square and transformed it into a thoroughfare, with unending alterations in traffic circulation. One of the facades is located in a narrow street with heavy traffic of cars and buses causing an accumulation of smoke and air pollution. These causes, among others, are the particular reasons that provoked the specific deterioration of the building. The same material shows different pathologies with different orientation conditions, sunlight, temperature, and location in the building. These pathologies range from alveolarization to salt formation with different morphologies, scabs, efflorescence, and flakes. The average climatic conditions of the city of Valencia correspond to a relative humidity of $65 \%$, temperature $18.3^{\circ} \mathrm{C}$, predominantly insolation on the southwest façade, and prevailing winds of southeast.

\section{Materials and Methods}

The stone that characterizes the Church of Santos Juanes (Figure 1) dates from the reconstruction work carried out in 1608. Various fires in the 13th, 14th, 16th, and 20th centuries caused the destruction of many of the temples files, leaving work contracts regarding the church and its extension as the only documents available. These contracts found at that time 


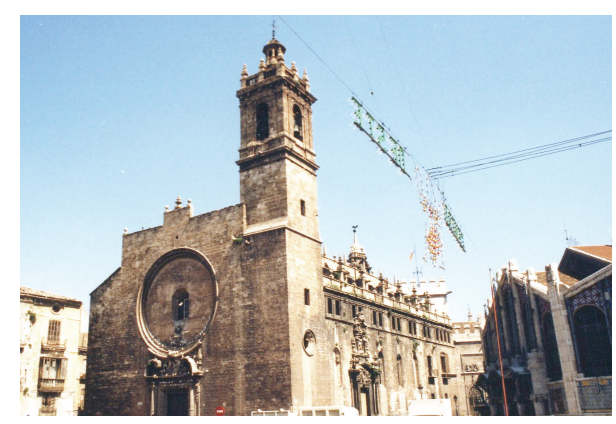

Figure 1: Overview of the church of Santos Juanes.

required the stone used for the building to come from the quarry of Tos Pelat, probably because that was the source of the original stone used for the building.

The stone from this quarry is a type of limestone popularly known as tosca (coarse) and is the main material used in many Valencia monuments [3].

We assume that this was the stone traditionally used in the stonework building of this church. Since there is no historical data on the construction of the church or on the quarries from which the stone used in its different phases of construction was obtained, we will base our classification of rocky material on the building's most important historical periods in which building work was carried out. The first classification of stone material refers to the most important historic periods of works carried out in the building and from this classification different samples were obtained corresponding, firstly, to the work of Gothic masonry of the church (the 15th and 16th centuries) and, secondly, to Baroque works and reconstruction (the 17th and 18th centuries).

The stone extracted belongs to a group of carbonated rocks formed by precipitated chemical whose composition, based on calcite, consists of almost invisibly variable concentrations of clay that are found. They are a lagoon limestone with organic remains of plants and nodules and not very significant variable concentrations of clay.

This limestone belongs to a type of rocks with a unique structure with a significant strip.

2.1. Implementation of the Identification and Classification Methodology of Stone Material. Following RILEMs [4], recommendations, sampling in both the quarry and the building, were carried out and suitable material fragments for sampling were obtained.

In the samples obtained from quarries that are currently unexploited, quality changes in quarry stratigraphy were taken into account and the most representative fragments from the areas that seemed more likely to have been previously exploited and based on historical documentation were chosen.

In the samples obtained from the building, the different types and morphologies of alteration were taken into account according to their orientation and exposure to atmospheric agents. The following plan shows the historical constructive evolution of the building's most relevant moments (Figure 2), and the following samples were obtained as shown in Table 1.

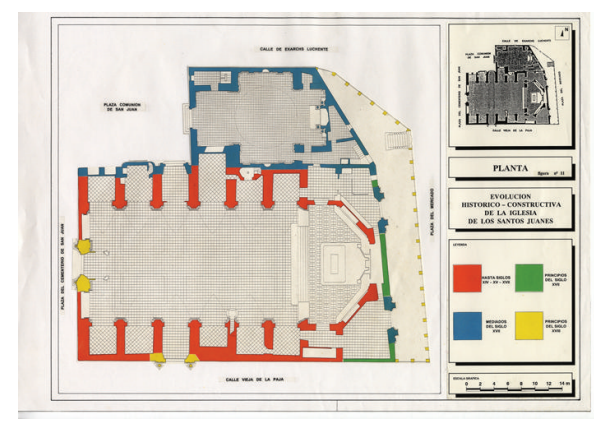

FIgURE 2: The historical constructive evolution of the church of Santos Juanes.

The pieces of equipment used were as follows:

(i) LEICA binocular loupe, model MZ APO, with $512 \mathrm{x}$ increase capacity and a resolution of 600 line pairs $/ \mathrm{mm}$, belonging to the Electron Microscopy Service of the Universitat Politècnica de València (Spain),

(ii) Zeiss Axioskop petrographic microscope, belonging to the laboratory of Research Technical Services of the University of Alicante (Spain),

(iii) JEOL Scanning Electron Microscope model JSM 6300 with an accelerating voltage of 0.2 to $30 \mathrm{kV}, 10 \mathrm{x}$ to 300000x magnification capacity ( $\mathrm{wd}=39 \mathrm{~mm}$ ), and secondary electrons resolution of $3.5 \mathrm{~nm}(30 \mathrm{Kv}$ and $\mathrm{wd}=8 \mathrm{~mm}$ ); further, it is equipped with a light elements microanalysis system of Oxford Instruments, Inca energy 250 model, belonging to the Electron Microscopy Service of the Universitat Politècnica de València (Spain).

Philips PW 1404 spectrometer with Sc-Mo X-ray tube has been used in the Geology Laboratory of the National Museum of Natural Sciences (Madrid, Spain). Quantitative determinations were made using the Panalytical-Phillpes IQ+ software, with the CNRS-France straight calibration standards.

Mercury injection analyses were carried out to determine the porous system obtained from the fraction determined through the analyses at the AICE institute (Research Partnerships of Ceramics Industries of Spain). The range of pores explored was between $300 \mu \mathrm{m}$ and $0.07 \mu \mathrm{m}$ in diameter. The purpose was to characterize the mother rock, whilst the cavities or large pores of these stones, which can be easily observed, are not determined following this technique.

\section{Results and Discussion}

The stone material used in the building is formed by calcite limestone which leaves large pores or cavities and large secondary crystallinity. In turn it consists of banded carbonates that arranged colorful different alternating bands creating more and less porous parts which are arranged parallel to the strata of the formation. Its pores are interconnected, the gaps are of very variable sizes and can be attributed firstly to primary intergranular porosity and secondly to 
TABle 1: Position samples. Quarry samples: C-1, C-2, and C-3.

\begin{tabular}{ll}
\hline & Building samples \\
\hline M-1 sample & Coating in a flaked off state from the right façade. Market square. \\
M-2 sample & Sample from the molding of the right base in the right façade. Market square. \\
M-3 sample & Central relief sample. Market square. \\
M-4 sample & Left façade sample. Market square. \\
M-5 sample & Fragment obtained from the statue at the foot of the exterior wall of the church. Market square. \\
M-6 sample & Sample of the jamb post of one of the upper gaps affected by the fire. Market square. \\
M-7 sample & Fragment obtained from the jamb post of an upper gap. Calle Vieja de la Paja. \\
M-8 sample & Fragment obtained from the right column in the façade. Calle Vieja de la Paja. \\
M-9 sample & Sample obtained from the upper pinnacle. Market street. \\
M-10 sample & Fragment obtained from the buttress. Calle Vieja de la Paja. \\
M-11 sample & Fragment obtained from the upper face. Calle Cementerio de San Juan 16th. \\
M-12 sample & Fragment obtained from the upper face, partially covered by mortar. Calle Cementerio de San Juan. \\
M-13 sample & Fragment from the upper ashlars. Calle Vieja de la Paja (Centuries). \\
M-14 sample & Mortar for fixing ashlar. \\
M-15 sample & Fragment from the base of the column in the street façade of Comunión de San Juan. \\
M-16 sample & Fragment from the left column in the street façade of Calle Vieja de la Paja. \\
\hline
\end{tabular}

secondary porosity of modic type. This stone is a microgranulated limestone without predetermined structure with a high porosity and large cavities. It has good cementing recrystallization areas where perfect crystals (Figure 6(a)) and little stratification develop. In parts of fresh samples, we can see how the recrystallization is massive, with just cement, giving an aggregate of crystals. The calcite crystals are tabular rhombohedra with perfect faces and growth planes around the pores are observed.

One of the objectives of characterizing the porous system of rock is to find out its susceptibility to the action of soluble salts and, therefore, its morphology of deterioration. The composition of materials is closely related to other salt intrusion causes, wherein the porous structure performs a key role in the mechanism of deterioration $[5,6]$. It is a known fact that a fluid's capacity for movement inside stone depends on its open porosity and therefore on its capillary structure, pore diameter, and means of access. The amount of humidity present in rocks, whether from capillary attraction or by absorption of water vapor, depends on the characteristics of the material itself as well as the ambient conditions.

The drying processes, to the same conditions of placement, are also conditioned by the structure of the material. Evaporation from a surface also depends on external factors, by which we mean the conditions adjacent to the surface, and the internal factors related to the movement of water on the surface [7] as well as the duration of wet/dry cycles [8].

Porous materials (stone and brick) have finer pores than the terrain. This is important to determine the capillary absorption properties of these materials and therefore the capillary suction is proportionally greater and dominates the fluid movement [9].

In materials in which water can move easily, drying takes place from the surface through molecular migration of the water which changes to the vapor state. This happens in this way if the movement of water, depending on the capillary structure, is fast enough to compensate for the loss by evaporation. Then the surface can dry before all the pores in the interior are empty. The water front withdraws to the interior of the wall and the speed decreases, which tends to stabilize the water content and critical dampness content [7].

\subsection{Characterization of the Material's Behavior: Testing for} Material Deterioration. The first area where we defined our work introduces us to the characteristics of the material regarding its porosity. Limestone porosity was measured with mercury intrusion porosimetry (MIP). The analysis carried out through mercury injection porosimetry determined the characteristics of the matrix rock. An analysis was carried out on the different samples collected at the monument and on different points of the same sample where heterogeneity of the mass could be clearly observed.

The averages of the tested samples were obtained and divided into groups according to the date of construction and the date they were quarried. Work was always carried out in the inside part of the rock not affected by deterioration.

Table 2 shows the results obtained for each of the samples. The graphic method represents the data of the analysis porosimeter and allows seeing the diameter of the pore. The graph of the accumulated distribution shows us the volume of pores depending on the logarithm of the diameter of the pores. By comparing the results of C-1 samples to the others a difference in the values of the volume of open pores can be observed. That difference also exists in the value of the average radius of the pores (Table 2). This fact together with other observations allows us to determine that, in terms of the porous system, the quarry sample is not comparable to the building samples.

The selected samples have been studied with a binocular loupe and a petrographic microscope.

Figure 3 shows the main samples M-9, M-13, and M-12 correspond to parts of the building that historically belong to the second most important building period of the temple. The values are similar when comparing the volume of open 


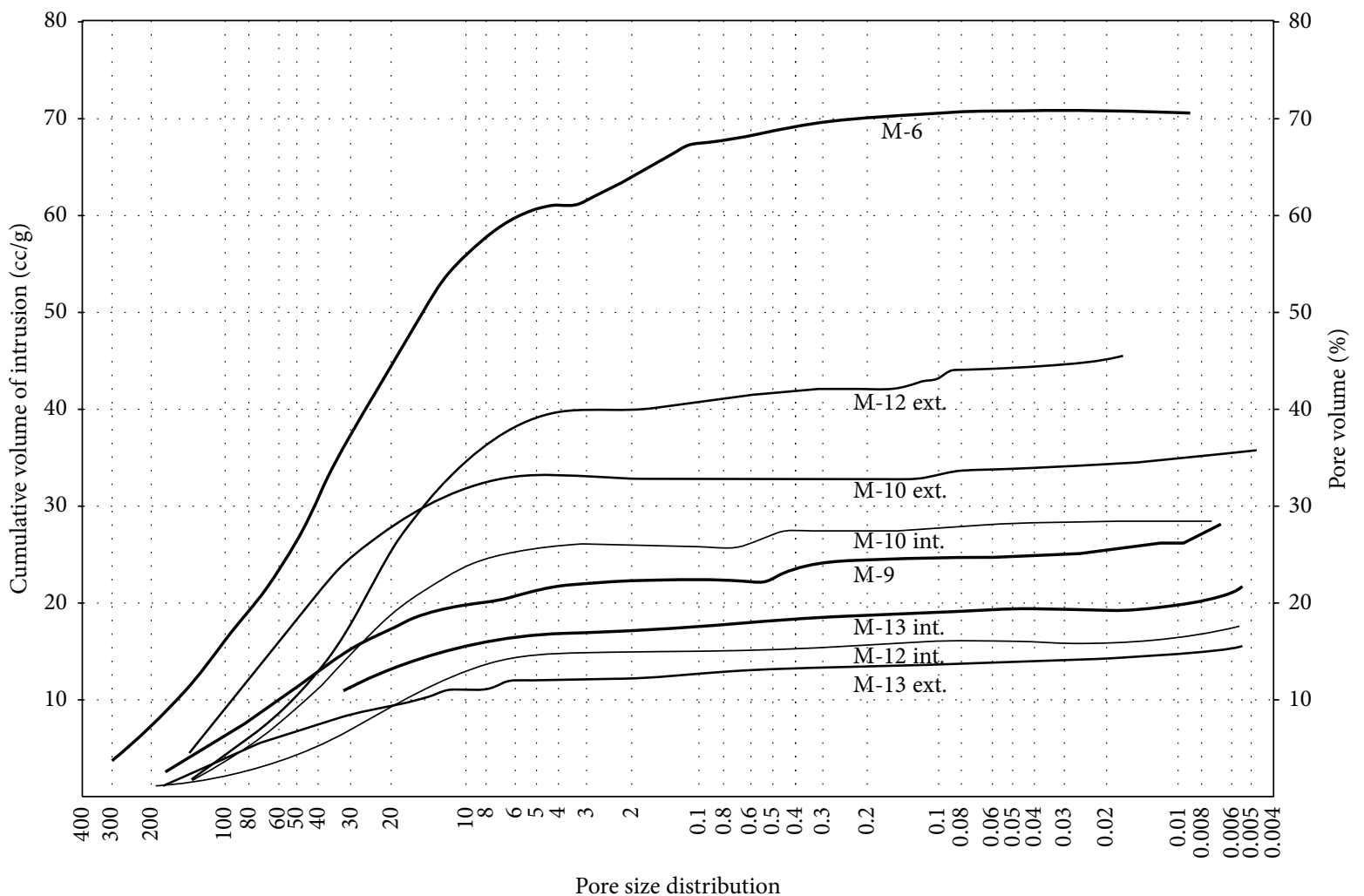

FIGURE 3: Graphical representation of pore diameter.

TABLE 2: Mercury porosimeter results.

\begin{tabular}{lcccccc}
\hline Sample & $V_{\text {Total }}$ & AT & PV & PS & SD/H & \%CAP \\
\hline M-6 & 0,0726 & 0,6177 & 30,8054 & 0,0136 & 2,8466 & 30,4158 \\
M-9 & 0,0252 & 0,9074 & 39,7126 & 0,1191 & 3,0938 & 9,0743 \\
M-10 int. & 0,0610 & 2,1220 & 32,8054 & 0,0087 & 3,2522 & 18,1487 \\
M-10 ext. & 0,0723 & 1,3552 & 63,5922 & 0,0129 & 3,1726 & 21,5095 \\
M-12 int. & 0,0341 & 0,9121 & 24,9927 & 0,0090 & 3,0705 & 11,5950 \\
M-12 ext. & 0,0939 & 1,5459 & 25,8301 & 0,0114 & 3,2322 & 25,8787 \\
M-13 ext. & 0,0332 & 1,8967 & 30,8691 & 0,0103 & 3,2266 & 9,4104 \\
M-13 int. & 0,0214 & 1,1263 & 36,9408 & 0,0119 & 3,2516 & 5,3774 \\
C-1 & 0,0113 & 1,1768 & 11,8981 & 0,0105 & 3,0312 & 4,3691 \\
\hline
\end{tabular}

$V_{\text {Total }}$ : intrusion total volume cc/g.

At: porous total area $\mathrm{m}^{2} / \mathrm{g}$.

Fi PV: porous average diameter (volume) $\mu \mathrm{m}$.

Fi PS: porous average diameter (area) $\mu \mathrm{m}$

$\mathrm{SD} / \mathrm{H}$ : sample density with $\mathrm{Hg}$ filled porous. Sample density with closed porosity $\mathrm{g} / \mathrm{cc}$.

\% Cap: $\mathrm{Hg}$ volume \% which has penetrated into the sample.

pores of the interior parts of the stones, as is the average diameter of their pores, but are less than those obtained in the M-10 samples which correspond to the first phase of the construction of the building.

The M-6 sample also corresponds to the first stage of the construction of the building, but the value it gave cannot be considered representative or comparative to sample M-10 because it comes from the part of the building which suffered many fires. However, the part of the sample does correspond to an intermediate zone between the superficial and internal one.

Of all the different samples obtained, parts corresponding to the internal part of the stone as well as other parts corresponding to the external part close to the surface crust were selected from samples M-10, M-12, and M-13. The parts extracted in the zone show an increase in the volume of open pores in the external part, which in turn increases the average diameter of the pores' volume.

M-10 belongs to a sample extracted from the buttress of building, in the upper part of the zone that corresponds to Vieja de la Paja street which was subjected to the effects of rain water. This corresponds to a part of the building made up from a layer of crust formed by carbonatation and soluble salts deposits caused by the flow of the water.

M-12 has a bigger increase in the volume of pores but shows the same size of average diameter of the pores. M13 has a significantly lower volume increase of open pores from the internal to the external parts and indeed the average diameter of the pores is bigger in the internal part of the sample. We should remember that the sample corresponds to the high part of the building looking on to Vieja de la Paja street, covered by a calcium sulfate crust which seals the surface, as well as the carbonate which has accumulated in the pores causing the surface to stagnate, as we can observe in Figure 6(c), all of which can cause the reduction of the average pores radius. 


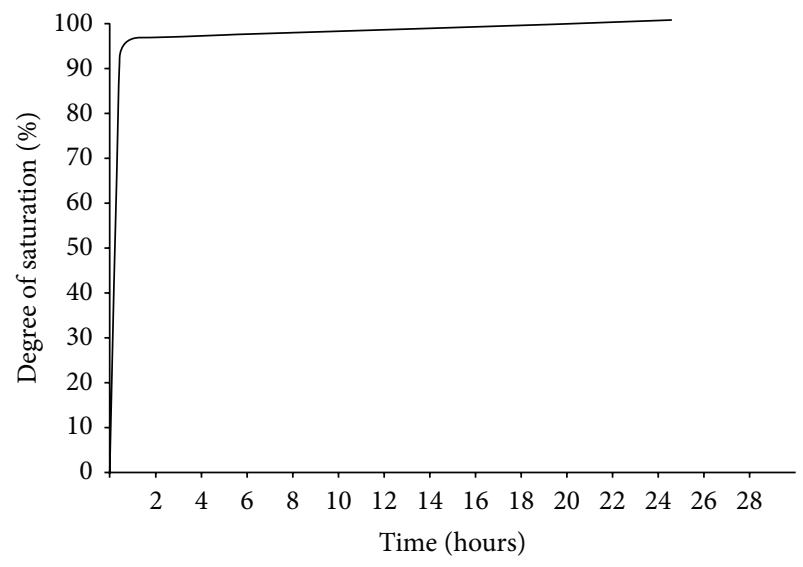

(a)

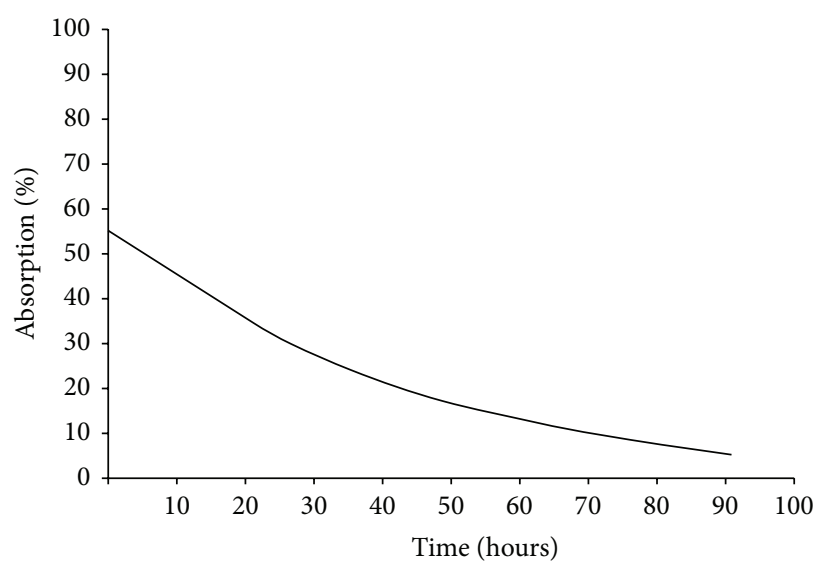

(b)

Figure 4: Absorption (a) and desorption (b) curves.

Parts of the sample that were not affected by the layer of mortar were chosen from sample M-12. This stone, with a considerable increase in open porousness, approximately maintains the same diameter average of the pores and corresponds to the part of the building that was most subjected to the effects of rain water, causing a decalcifying effect in the most external part.

\subsection{Conditions That Influence Crystallization in the Deposition} of Salts. The conditions related to crystallization and the deposition of salts under study concern the nature and concentration of salts, the texture of the material, and those related to evaporation.

A sample of the building was taken by obtaining fragments of material, taking into consideration the different types and morphologies of change depending on orientation and exposure to atmospheric agents. From observations made with a binocular magnifier, petrographic microscope, and scanning electronic microscope as well as tests with a mercury porosimeter we were able to characterize the rock as very porous, the pores of which were found to be interconnected.

The size of these empty spaces varies considerably and can be attributed to primary intergranular porosity and secondary porosity of the modic type. The porous morphology corresponds to minute channels with walls packed with microcrystal making them irregular in shape, both in the interior and exterior of the pores as well as the outer part of the latter.

We also checked the water saturation and effusion capacity of the material, plotting their corresponding curves, which confirm that we are dealing with a highly porous rock and that the drying of the surface is slow and diffuse caused by the flow of water to its interior (Figure 4). The stone has high connectivity and variations in pore size or interpore connections. The absorption curves for these rocks could be broken down into two straight lines exhibiting a gradual change of slope between the initial and final phase [10].

This pore distribution, with few large and numerous small pores, promotes the formation of salt crystals. Their desorption curve (Figure 4) showed that rock underwent slow, on the whole, evaporation where moisture was retained inside the pore system longer. Salts crystallization can occur if the solution is saturated or supersaturated [5]; therefore, it is possible that the concentration is constant and the temperature decreases, the solution reaches the saturation condition, and a low crystallization occurs. If evaporation occurs at a constant temperature, the concentration of the solution increases rapidly at the end of the capillaries and saturation is reached. The most common is that the combination of decreased temperature and increased concentration of the solution occur simultaneously.

3.3. Nature and Concentration of Salt. The influence of the concentration of soluble salts as a condition for crystallization is evident. The greater the concentration is, the bigger the quantity of soluble salts can fill the pores. If there is a smaller quantity, the salts can be absorbed by capillaries and carried to the surface without causing too much harm [11]. The most serious deterioration is originated by the salts that crystallize for a given variable quantity of water of crystallization, when the temperature which conditions this transformation is near to ambient temperature. Thus, the deteriorating action of the salts is manifested especially when this crystallization is in anhydride form or in its weakest state of hydration, which can occur at lower temperatures.

Depending on the temperature, the relative humidity, and the relationship between the pressure of the water vapor and the vapor pressure of the hydrated salt, a rhythmic contraction and expansion on the walls of the pores develop depending on the pressure of hydration. When this is higher than the resistance of the surface of the wall, it breaks through leaving the stone more porous and more sensitive to the future action of dampness and salts.

Tests carried out on different samples (Table 3) regarding the salt content show that those corresponding to stone materials with the greatest volume of open pores contained a higher percentage of sulphates.

Salts present in the stone samples were analyzed by scanning electron microscopy with energy dispersive X-ray 


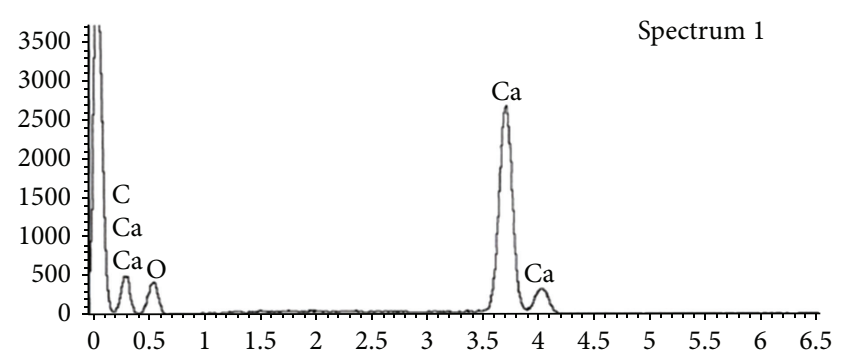

(a)

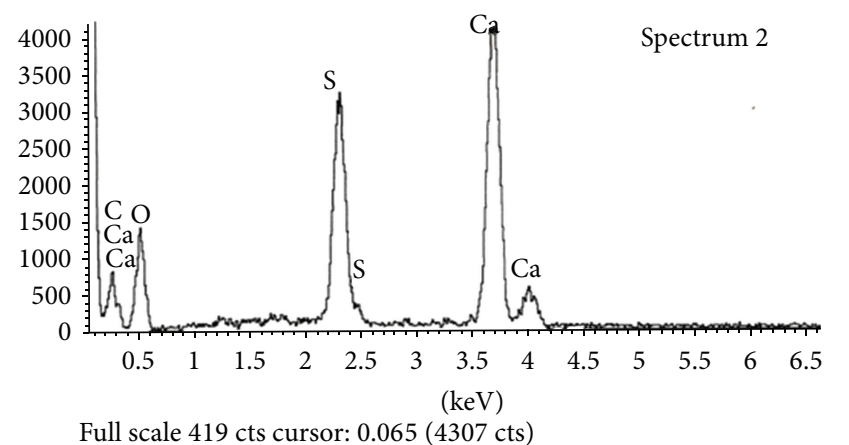

(b)

FIGURE 5: X-ray diffraction analysis.

TABLE 3: Salt content.

\begin{tabular}{lcccccc}
\hline Number & $\mathrm{Cl}^{-}$ & $\mathrm{Ca}^{++}$ & $\mathrm{Mg}^{++}$ & $\mathrm{SO}_{4}{ }^{--}$ & $\mathrm{CO}_{3} \mathrm{H}^{-}$ & $\mathrm{Na}^{+}$ \\
\hline C-1 & 7 & 23.0 & 3.6 & 19.2 & 79.3 & 9.2 \\
M-9 & 28 & 59.0 & 3.0 & 24.0 & 126.8 & 4.6 \\
M-6 & 7 & 29.6 & 3.6 & 24.0 & 85.4 & 5.29 \\
M-12 & 28 & 158.0 & 5.6 & 384.0 & 68.3 & 20.7 \\
M-10 & 2 & 32.0 & 3.0 & 33.6 & 122.0 & 6.9 \\
\hline
\end{tabular}

Data in $\mathrm{mg} /$ liter with $10 \mathrm{gr}$ of sample in $100 \mathrm{~mL}$ of distilled $\mathrm{H}_{2} \mathrm{O}$.

spectroscopy (SEM-EDX) to characterize the salt mixture with surface damage. Analysis of the fresh, altered, and mainly physical-chemical meteorized samples has been compared by X-ray diffraction. Sulfur peak presence has been observed in monument samples. $\mathrm{Pb}$ and $\mathrm{Na}$ presence in some samples are sporadic anomalies due to samples spatial orientation in front of gas emulsions from combustion and saline seaside environment; an example is shown in Figure 5 and Table 4.

Coal burning transforms sulfur into sulfur dioxide, one of the main atmospheric pollutants during the past four centuries. Limestones and calcareous sandstones are prone to developing crusts of hydrated calcium sulfate from the reaction of the moist stone (rich in calcium carbonates) with sulfur dioxide gas that has been converted to sulfuric acid or to an intermediate sulfite salt by an oxidation reaction [12]. These stones surfaces develop a surface crust of gypsum, blackened by incorporation of soot particles and organic matter.
3.4. Texture of the Material. The formation of crystals is linked to the texture of the material itself, regarding its morphology, shape, and size of its pores. Therefore, a crystalline structure grows by adding layers of material to the external surface when it is in contact with a solution which carries the necessary material for its growth. When the crystals grow in contact with the surface of the pores, there is always a thin coating of solution due to capillary attraction and absorption. We must take into consideration the fact that a solution can become supersaturated with respect to a crystal under low pressure, the case of crystal growth in large pores, while the same tends to dissolve a crystal that is under high pressure, the case of crystal growth in small pores [13]. For this reason the process is more feasible in material made up of many small pores that feed the growth of crystals in their large pores; these are fewer in number. The stone material under study fits this case. This fact can be seen in the microphotographs taken of the different samples of stone material extracted from the building where we can observe the formation of geodes in the interior of the microspores (Figure 6(a)).

3.5. Conditions of Evaporation. When evaporation takes place through the pores on the surface, the soluble salts that can crystallize on the surface form deposits that are commonly called efflorescence. The distribution of efflorescence on the surface of a wall generally depends on its height above ground level and the wall's geometrical shape. It may be concentrated in certain parts of the wall, often found in the corners of a building between dry and damp areas, at the edge of a damp area which has risen, below roofing and cornices or below defective guttering.

The performance of the stone when exposed to environmental agents depends on the building's orientation and the building element involved: basement, columns, arches, and cornices [14].

The evaporation rate in the crystallization of soluble salts on the surface of badly ventilated areas is lower than the water replacement rate by capillary migration in the interior of the wall.

The street receives many hours of sunshine; thus it is possible that the high solar irradiation influences transfer via humidity, evaporation, and salt crystallisation, as well as determining and increasing the frequency of salt crystallisation cycles [15].

One part of the salts may remain in the internal layers of the stone. Crystallization of the salts takes place in the interior if the surface evaporation takes place in a relatively short period of time and most of the evaporation takes place below the surface. The crystallization of salts is known in terms of crypto-effloresce [16].

In many cases liquid does not form on external surfaces in which the evaporation of water through the pores is very rapid, and thus it remains dry since the water evaporates at a greater rate than the interior water flow is refilled.

In these cases the migration of the solution towards the external surface is slower and crystals form and grow in the pores and fissures, along a plane at a certain distance below the surface [17]. The subefflorescence formed in this way 

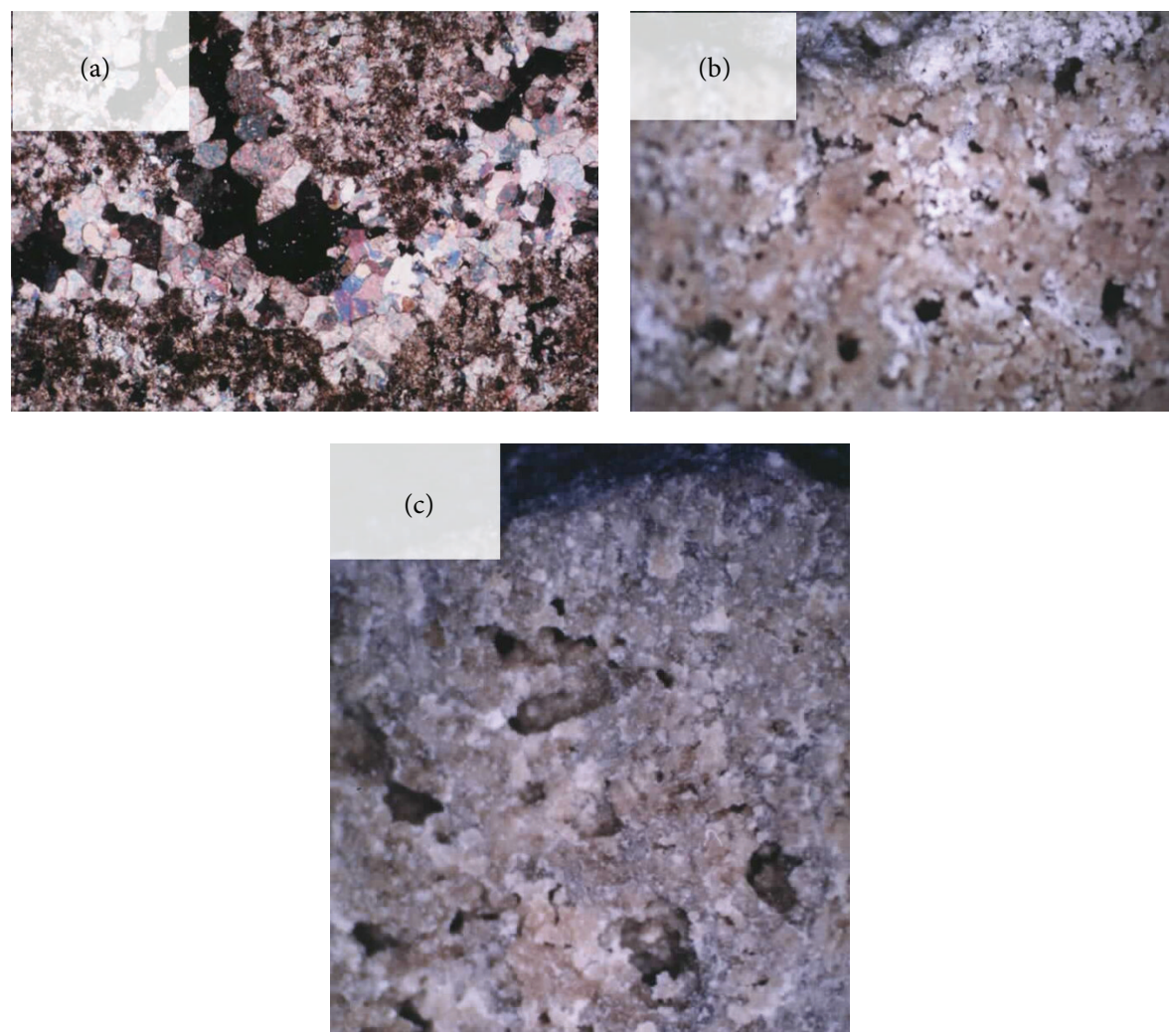

FIGURE 6: (a) View of thin section NP40X. Geologic process or natural process of pore filling by calcium cement. (b) View through a binocular magnifier. Advance of the process of precipitation by formation of salts in a porous mass. (c) Transverse cut from the least affected part (interior zone) to the most affected.

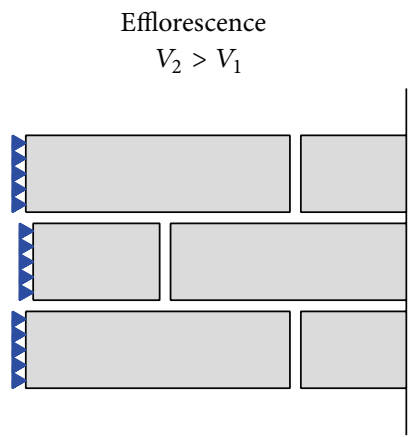

(a)

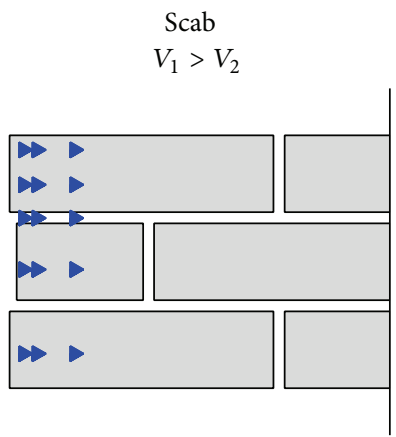

(b)

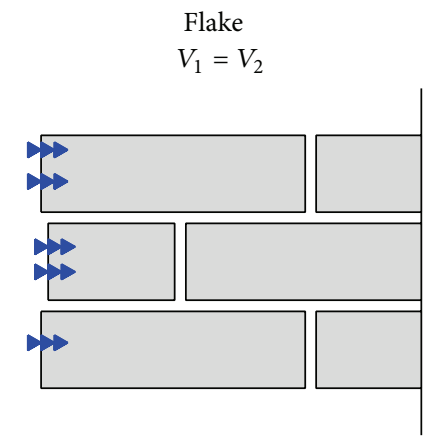

(c)

FIGURE 7: Material deterioration morphology produced by the crystallization of salts.

exerts more pressure on the rest of the stone materializing in the interior by a desegregation, exfoliation, of the acicular type of the surface layer or by the formation of ampullae. The thin layers which are formed are of secondary origin, and they run parallel to the surface and are composed of alternating bands of transforming minerals. These layers are separated from the rest of the rock and if water is allowed to enter, it can cause processes of gelling and the mass can become detached, leaving the interior prone to rain erosion. Maximum deterioration occurred when the top eroded and the patches worked loose from the surface (spalling) [18].
When the stationary state is reached, that is to say, when the rate of diffusion of water vapor from the dry stone surface is dynamically balanced by the rate of capillary migration of the solution from the dry and wet zone, a compact sheet of material, known as scale, is formed on the external surface (Figure 7).

Depending on evaporation rate $\left(V_{1}\right)$ and the migration speed of the water towards the surface $\left(V_{2}\right)$ different morphology deterioration occurs by crystallization of the salts in the material [5]. 
TABLE 4: X-ray data of sample M13.

(a) Vert. $=1000$ counts, disc $=1$, preset $=100$ secs, elapsed $=100$ secs

\begin{tabular}{lcl}
\hline Energy & Counts & X-ray lines \\
\hline 1.28 & 960 & Mg KA1, Mg KA2, Mg KB1 \\
1.51 & 1739 & Al KA1, Al KA2 \\
1.76 & 8100 & Si KA1, Si KA2 \\
2.33 & 28315 & S KA1, S KA2, Pb MA1, Pb MA2 \\
2.65 & 1069 & Cl KA1, Cl KA2, Pb M2N, Pb MG2, Pb MG1 \\
3.33 & 2771 & K KA1, K KA2 \\
3.71 & 33672 & Ca KA1, Ca KA2 \\
4.03 & 4164 & Ca KB1, Ca KB3 \\
5.40 & 399 & Fe KA1, Fe KA2 \\
\hline
\end{tabular}

Accelerating voltage: $22.0 \mathrm{KEV}$, incidence angle: 70.0 degrees.

$\mathrm{X}$-ray emergence angle 36.1 degrees.

(b) Standardless EDS analysis (ZAF corrections via MAGIC V)

\begin{tabular}{lcccc}
\hline $\begin{array}{l}\text { Element and } \\
\text { line }\end{array}$ & $\begin{array}{c}\text { Weight } \\
\text { percent }\end{array}$ & $\begin{array}{c}\text { Atomic } \\
\text { percent }^{*}\end{array}$ & $\begin{array}{c}\text { Precision } \\
2 \text { sigma }\end{array}$ & $\begin{array}{c}\text { K-ratio** } \\
\text { iter. }\end{array}$ \\
\hline Mg KA & 0.66 & 1.50 & 0.08 & 0.0041 \\
Al KA & 1.23 & 2.51 & 0.09 & 0.0091 \\
Si KA & 4.29 & 8.43 & 0.15 & 0.0360 \\
S KA & 15.35 & 26.44 & 0.27 & 0.1619 \\
Cl KA & 1.60 & 2.48 & 0.10 & 0.0141 \\
K KA & 2.74 & 3.87 & 0.14 & 0.0249 \\
Ca KA & 31.05 & 42.78 & 0.49 & 0.2920 \\
Fe KA & 0.69 & 0.69 & 0.11 & 0.0077 \\
Pb KA & 42.39 & 11.30 & 0.72 & 0.4484 \\
TOTAL & 100.00 & & & \\
\hline
\end{tabular}

${ }^{*}$ Note: atomic percent is normalized to 100 .

${ }^{* *}$ Note: $K$-ratio $=K$-ratio $\times R$, where $R=$ reference (standard)/reference (sample).

Normalization factor: 0.839 .

Efflorescence is the salts crystallization on the outer surface of the material. Scab is a compact film on the outside of the material and is identified by its hardness, its colour (black scabs), or products containing carbonaceous pollution (soot, dust, etc.). Flake is a sheet of a few millimetres thick that emerges parallel to the surface.

(i) Efflorescences. Salt crystals, such as potassium and sodium sulphates, are common in walls, especially in the summer months. Efflorescent salts form a mark with the position of the evaporation fronts, which may be on the surface of porous materials with the same frequency or just below the surface within the pores themselves.

The origin of the ions forming soluble salts is very diverse: (a) By leaching of rocks, mortars, and other materials, and restoration. (b) Pertaining to the subsoil. (c) By deposits of natural products or anthropogenic atmospheric pollution. (d) Generated by the metabolism of organisms. (e) Other origin. The ion activity of the solutions that rise buildings walls by capillary depends on the nature of the subsoil and activity in the environment. In the atmosphere are suspended particles, aerosols, and gases whose ions are able to form soluble salts deposits on the stones [19].
Consequences of salt accumulation are as follows. Salts can block pores and capillaries through water evaporation and, therefore, drive up the wet front thereby increasing humidity [20] and material damage occurs by a constant dissolution and recrystallization of certain salts given by humidity and temperature changes. The salts of sodium sulfate deposited from groundwater can be particularly destructive to buildings and monuments [21].

(ii) Black Scabs. In fact, black scabs are formed by gypsum (a salt), but they have a high incidence in urban areas.

Black scab is a layer of black or dark grey composed of gypsum and rock minerals.

Sometimes, scabs have spongy morphologies and a certain thickness, up to several centimeters. They cause sandification of rock overlain [22].

(iii) Flakes. A series of flakes occurs due to the deterioration in the stone. The deterioration in the stone material is exfoliation as we can observe. Lifting and separation of one or more layers (altered or not) of uniform thickness (several millimetres) are produced parallel to each other and regarding structural or weakness sections of the stone. 


\section{Discussion and Conclusions}

Checking the deterioration of the material showed that depending on the conditions of exposure, in some zones more surface layers were formed which took on crust, scale, and other shapes, made up by deposits of air pollution, air deposits, sulfate formations, and flows of calcium carbonate.

The porousness of these surface layers varies depending on their initial parameters depending on possible stagnation due to salt accumulation, mechanical deposits, calcium sulfate formations, or increasing this porosity due to decarbonatation and decementation of the material carried away by the water.

The different morphologies of deterioration originated by the formation of soluble salts were found to be distributed throughout the building depending on its orientation. In facades exposed to greater ventilation and more sun the formation of internal crusts, exfoliation, and ampullae was observed.

The formation of efflorescence was observed in less exposed areas (Figure 6(b)) and where a balance between the rate of evaporation and the flow of water to the surface existed, the formation of scales was observed.

For different reasons the stone elements of the buildings are covered by a more or less superficial coating, since it takes the form of thicknesses and shapes which vary from simple incoherent stratifications of dust to what can be called sticky deposits of material in the form of scales, crusts, and so forth. The formations of this coating are due in part to, and for this reason are detectable by, the impoverishment of the interior zones of the stone material and the resulting meteoric rate of development that has taken place in the stone material of the building where the formation of these layers culminates in the different factors that produced them, which are formed by

(i) a layer made up of deposits of salt by the formation of sulphates and by migration of carbonates,

(ii) an interior layer formed by deposits of carbonates and soluble salts produced by the flow of water,

(iii) another layer where decarbonatation and the beginning of decementation have occurred.

The thickness of this layer varies depending on the content and nature of the soluble salts, the reach of the water which is directly related to the texture of the material, and the evaporation conditions (Figure 6(c)).

Stone material presents different deterioration morphologies depending on its architectural elements. This element makes up part of the building and its degree of alteration is conditioned by its location and orientation-sun exposure, rain, wind, and so on.

Moreover, the building is located in an urban enclave where its particular location conditions, wide and narrow streets, traffic, and pollution all contribute even more to demonstrate the morphological diversity of the deterioration that this stone material shows.

\section{Conflict of Interests}

The authors declare that there is no conflict of interests regarding the publication of this paper.

\section{References}

[1] M. Sanchis-Guarner, La Ciutat de Valencia. Sintesi d'Historia $i$ de Geografía Urbana, Círculo de Bellas Artes de Valencia, Valencia, Spain, 1972.

[2] T. Simo, Barrio del Mercat. Valencia Centro Histórico. Guía Urbana y de Arquitectura, Institución Alfonso el Magnánimo, Valencia, Spain, 1983.

[3] S. S. López and Z. Doménech, Historia y Mensaje del templo de los Santos Juanes, Federico Domenech, Valencia, Spain, 1989.

[4] Rilem Commission 25. PEM, Essais recommades por mesurer l'álterationdes pierres et evaluer l'éfficacité des méthodes de traitatement recommandations provisoires, Materiaux et Construction, 1980.

[5] G. Cultrone, L. G. Russo, C. Calabrò, M. Uroševič, and A. Pezzino, "Influence of pore system characteristics on limestone vulnerability: a laboratory study," Environmental Geology, vol. 54, no. 6, pp. 1271-1281, 2008.

[6] D. Benavente, M. A. García del Cura, J. García-Guinea, S. Sánchez-Moral, and S. Ordóñez, "Role of pore structure in salt crystallisation in unsaturated porous stone," Journal of Crystal Growth, vol. 260, no. 3-4, pp. 532-544, 2004.

[7] M. A. Rossi, Patologías, técnicas de diagnóstico y terapéuticas en los materiales del Patrimonio Arquitectónico, E.U. Arquitectura Técnica, Valencia, Spain, 1988.

[8] L. Binda, G. Cardani, and L. Zanzi, "Nondestructive testing evaluation of drying process in flooded full-scale masonry walls," Journal of Performance of Constructed Facilities, vol. 24, no. 5, pp. 473-483, 2010.

[9] I. Ioannau, C. Hall, M. A. Wilson, W. D. Hoff, and M. A. Carter, "Direct measurement of the wetting front capillary pressure in a clay brick ceramic," Journal of Physics D: Applied Physics, vol. 36, no. 24, pp. 3176-3182, 2003.

[10] O. Buj, P. L. López, and J. Gisbert, "Characterization of pore system and their influence on decay rates caused by salt weathering on limestones and dolostones quarried in Abanto (Zaragoza, Spain)," Materiales de Construccion, vol. 60, no. 299, pp. 99-114, 2010.

[11] M. A. Rossi, R. Manarrossi, and R. Pietse Porne, Alterazione e Conservazione, Supplemento al no. 41/1987, Bullettino d'Arte del Ministerio per Beni Culturali e Ambientali, 1987.

[12] R. U. Cooke and G. B. Gibbs, Crumbling Heritage Studies of Stone Weathering in Polluted Atmospheres, National Power PLC and PowerGen PLC, Swindon, UK, 1993.

[13] R. J. Flatt, "Salt damage in porous materials: how high supersaturations are generated," Journal of Crystal Growth, vol. 242, no. 3-4, pp. 435-454, 2002.

[14] F. Veniale, M. Setti, and S. Lodola, "Diagnosing stone decay in built heritage. Facts and perspectives," Materiales de Construccion, vol. 58, no. 289-290, pp. 11-32, 2008.

[15] M. Louis, M. A. García del Cura, Y. Spairani, and D. De Blas, "The Civil Palaces in Gravina street, Alicante: building stones and salt weathering," Materiales de Construccion, vol. 2001, no. 262, pp. 23-37, 2001.

[16] C. M. Grossi and R. M. Esbert, "Las sales solubles en el deterioro de rocas monumentale: revisión bibliográfica," Materiales de Construcción, vol. 44, no. 235, pp. 15-30, 1994. 
[17] F. J. Alonso, P. Vázquez, R. M. Esbert, and J. Ordaz, “Ornamental granite durability: evaluation of damage caused by salt crystallization test," Materiales de Construccion, vol. 58, no. 289-290, pp. 191-201, 2008.

[18] R. Fort, B. Fernández-Revuelta, M. J. Varas, M. A. de Buergo, and M. Taborda-Duarte, "Influence of anisotropy on the durability of Madrid-region Cretaceous dolostone exposed to salt crystallization processes," Materiales de Construcción, vol. 58, pp. 289-290, 2008.

[19] M. P. Ortiz, Influencias del entorno ambiental en los procesos de degradación de la piedra de la catedral de Cádiz. Aproximación teórica y recomendaciones para la conservación [Ph.D. thesis], Universidad de Sevilla, 1998.

[20] A. Oliver, Dampness in Buildings, BSP Professional Books, Oxford, UK, 1988.

[21] H. de Clercq, Proceedings from the Conference on Salt Weathering on Buildings and Stone Sculptures, Technical University of Denmark, Copenhagen, Denmark, 2008.

[22] M. Ortega and E. M. Sebastián, Técnicas de Diagnóstico Aplicadas a la Conservación de los Materiales de Construcción en los Edificios Históricos, Junta de Andalucía, Sevilla, Spain, 1996. 

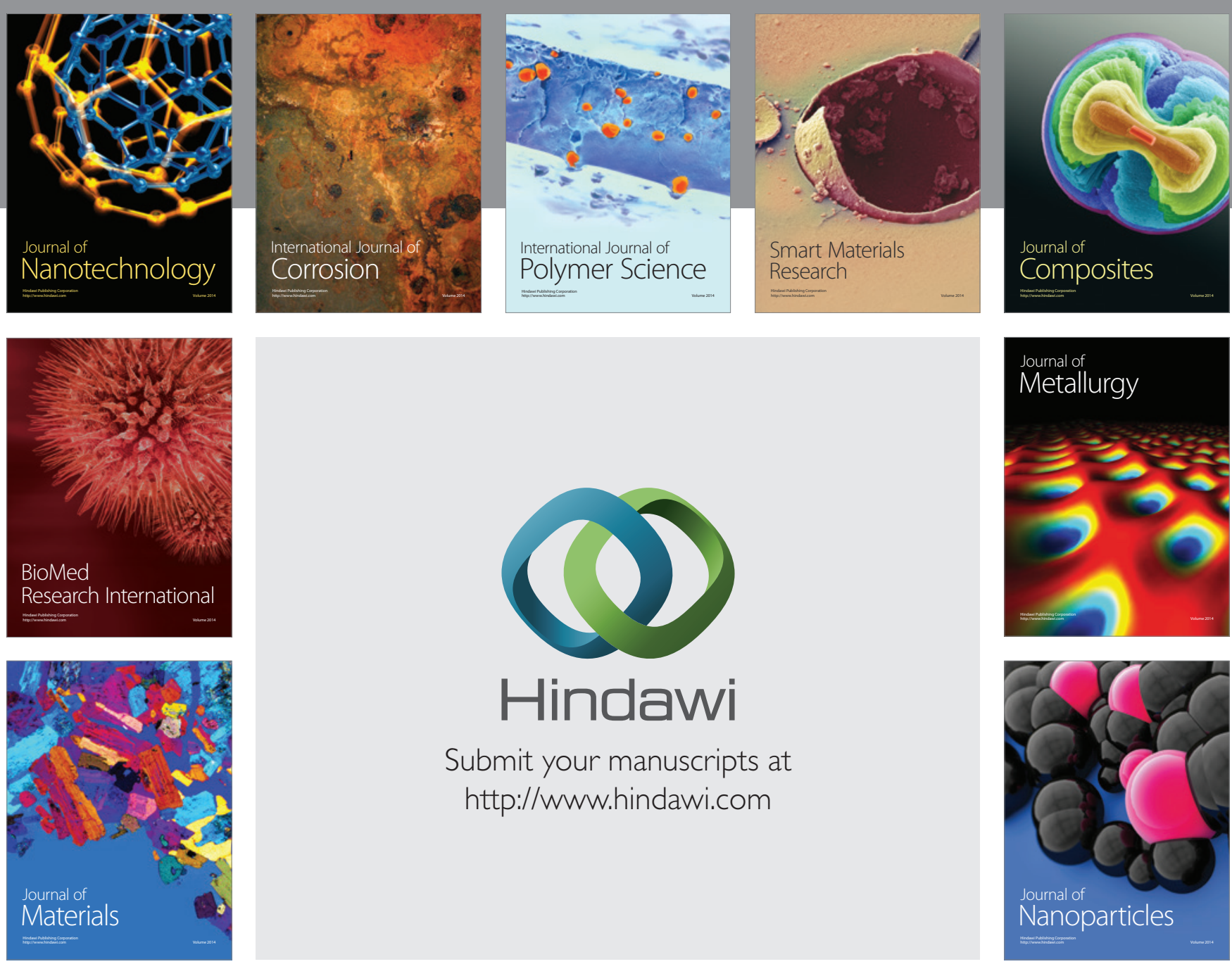

Submit your manuscripts at http://www.hindawi.com
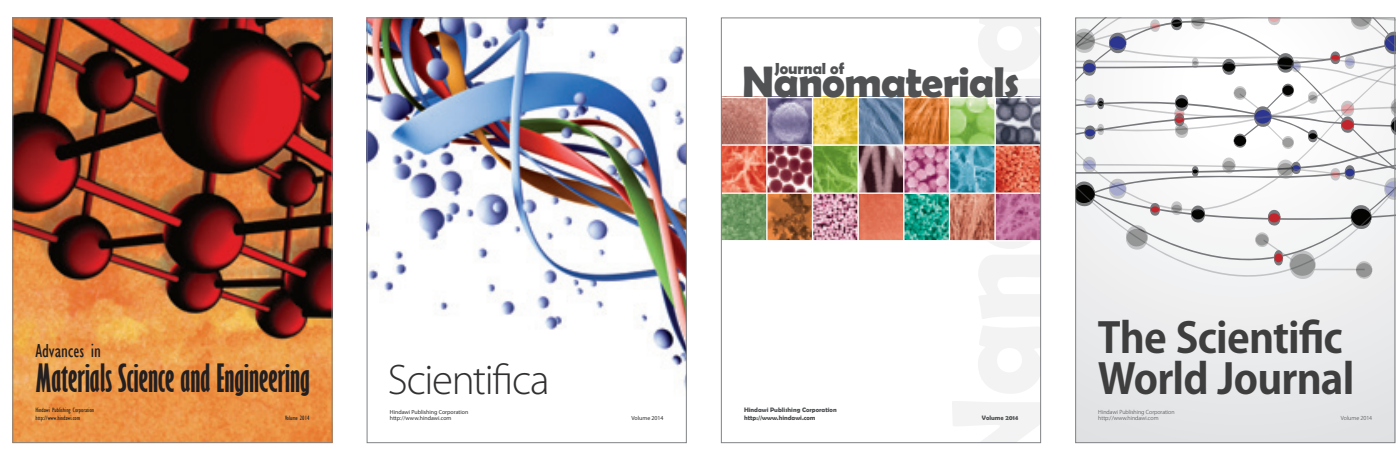

\section{The Scientific World Journal}
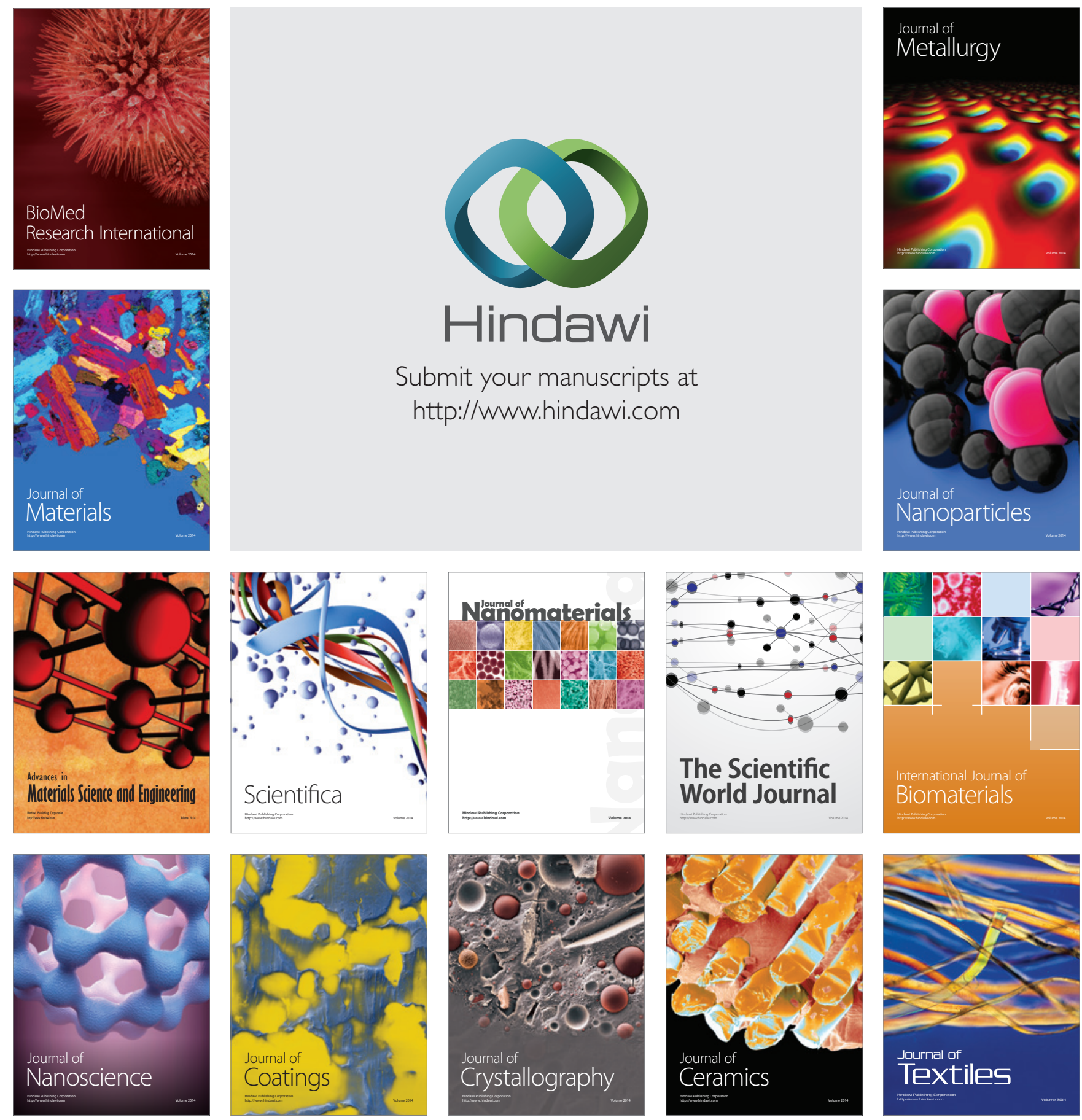